\title{
Staff Shortage in German Intensive Care Units During the COVID-19 Pandemic - Not only a Sensed Dilemma: Results from a Nationwide Survey
}

\section{Clemens Grimm}

Universitätsmedizin Göttingen: Universitatsmedizin Gottingen https://orcid.org/0000-0002-2903-8454

\section{Steffen Dickel}

Universitätsmedizin Göttingen: Universitatsmedizin Gottingen

\section{Alexandra Sachkova}

Universitätsmedizin Göttingen: Universitatsmedizin Gottingen

\section{Maria Popp}

Universitatsklinikum Wurzburg

\section{Martin Golinski}

Universitätsmedizin Göttingen: Universitatsmedizin Gottingen

\section{Falk Fichtner}

Universitätsklinikum Leipzig: Universitatsklinikum Leipzig

\section{Peter Kranke}

Universitatsklinikum Wurzburg

\section{Christian Seeber}

Universitätsklinikum Leipzig: Universitatsklinikum Leipzig

\section{Sven Laudi}

Universitätsklinikum Leipzig: Universitatsklinikum Leipzig

\section{Sebastian Voigt-Radloff}

Universitätsklinikum Freiburg: Universitatsklinikum Freiburg

Onnen Moerer ( $\nabla$ omoerer@med.uni-goettingen.de)

University Hospital Goettingen, Georg-August-University https://orcid.org/0000-0002-4210-388X

\section{Research}

Keywords: COVID-19, ICU, nurse-to-patient-ratio, physician-to-patient-ratio, nursing shortage

Posted Date: March 22nd, 2021

DOI: https://doi.org/10.21203/rs.3.rs-323586/v1 
License: (c) (i) This work is licensed under a Creative Commons Attribution 4.0 International License. Read Full License 


\title{
RESEARCH
}

\section{Staff shortage in German intensive care units during the COVID-19 pandemic - not only a sensed dilemma: results from a nationwide survey}

\author{
Clemens Grimm ${ }^{1 \dagger}$, Steffen Dickel ${ }^{1 \dagger}$, Alexandra Sachkova ${ }^{1}$, Maria Popp ${ }^{2}$, Martin Golinski ${ }^{1}$, Falk Fichtner ${ }^{3}$, \\ Peter Kranke ${ }^{2}$, Christian Seeber ${ }^{3}$, Sven Laudi ${ }^{3}$, Sebastian Voigt-Radloff ${ }^{4}$, Onnen Moerer ${ }^{1 *}$ and the \\ CEOsys Study Group
}

\begin{abstract}
Background: The surge in patients during the COVID-19 pandemic has exacerbated the looming problem of staff shortage in German ICUs possibly leading to worse outcomes for patients.

Methods: Within the German Evidence Ecosystem CEOsys network, we conducted an online national mixed-methods survey assessing the standard of care in German ICUs treating patients with COVID-19.

Results: A total of 171 German ICUs reported a median ideal number of patients per intensivist of 8 (interquartile range, IQR $=3 \mathrm{rd}$ quartile -1 st quartile $=4.0)$ and per nurse of $2.0(\mathrm{IQR}=1.0)$. For COVID-19 patients, the median target was a maximum of $6.0(I Q R=2.0)$ patients per intensivist or $2.0(I Q R=0.0)$ patients per nurse. Targets for intensivists were rarely met by $15.2 \%$ and never met by $3.5 \%$ of responding institutions. Targets for nursing staffing could rarely be met in $32.2 \%$ and never in $5.3 \%$ of responding institutions.

Conclusions: Shortages of staffing in the critical care setting are eminent during the COVID-19 pandemic and might not only negatively affect patient outcomes, but also staff wellbeing and healthcare costs. A joint effort that scrutinizes the demands and structures of our health care system seems fundamental to be prepared for the future.
\end{abstract}

Keywords: COVID-19; ICU; nurse-to-patient-ratio; physician-to-patient-ratio; nursing shortage

\section{Background}

The intensive care treatment of critically ill patients places high demands on staffing. In 2018, the German Federal Ministry of Health issued a regulation on minimum staffing standards (PpUGV) in so-called care-sensitive areas that has been updated in November 2020 [1]. In intensive care units (ICU) a maximal nurse-to-patient ratio of $1: 2.5$ during the day shift ( 6 a.m. to 10 p.m.), and $1: 3.5$ during the night shifts (from 10 p.m. to 6 a.m.) is mandated [1]. The German interdisciplinary society of intensive care medicine (DIVI) urges hospitals to implement nurse-to-patient ratios that do not exceed 1:2 during all shifts [2]. It is

\footnotetext{
${ }^{*}$ Correspondence: omoerer@med.uni-goettingen.de

${ }^{1}$ Department of Anaesthesiology, Emergency and Intensive Care Medicine, University Hospital Goettingen, Georg-August-University, Goettingen, Germany

Full list of author information is available at the end of the article

${ }^{\dagger}$ Equal contributor

Contact to CEOsys: sec@ifem.uni-freiburg.de
}

noticeable that the demand for care varies between the different countries. It can be assumed that this is due to different allocations of tasks. The strained staffing situation in intensive care units is a recurring topic in the political and scientific debate $[3,4,5,6]$. Critically ill COVID-19 patients in ICUs will presumably require staffing ratios that are at least as high as those required for non-COVID-19 patients. In addition, isolation measures take up additional time and resources. Reliable figures on the nursing and medical care situation during the COVID-19 pandemic have not yet been collected but could make an important contribution to informed health policy discussions [7]. The shortage of highly trained medical staff in German hospitals also manifests itself in health policy decisions, such as increasing the weekly working hours for nurses in some German states or suspending the staffing ratio during the COVID-19 pandemic [1,8].

Numerous studies demonstrate the correlation be- 
tween adequate quantitative and qualitative staffing and the likelihood of infectious and cardiac complications, surgical bleeding, decubital ulcers, occurrence of medication errors and critical incidents such as unplanned extubations $[9,10,11,12,13]$ which effects outcome, ICU and hospital length of stay [10]. The economic impact should not be underestimated since adequate staffing can be related to high-cost savings through early detection of complications outweighing staffing costs [14].

The staff-to-patient ratio has an important impact on the health of healthcare professionals and their job satisfaction [15]. This should be taken into account to prevent further endangering the long-term maintenance of medical care by the means of staff leaving or falling ill $[16,17]$.

This study analyzed data on staffing taken from a survey by the CEOsys consortium aiming at detecting variance and current standards of care for patients suffering from COVID-19 on German ICUs.

\section{Methods}

We performed a qualitative and quantitative analysis of a closed access (invitational only) national mixedmethod survey, which was conducted online from December 3rd to December 31st, 2020. The presented data are part of a larger assessment on current standards of care regarding COVID-19 in German intensive care units presented and discussed elsewhere. The survey was specifically sent via the German Interdisciplinary Association for Intensive Care and Emergency Medicine (DIVI) email distribution list to 3325 addressees, of which 2260 were physicians. Specific filter questions at the beginning of the survey ensured that only physicians in a leading position who had already treated COVID-19 patients on their wards participated in the survey. To avoid inadvertent multiple responses, a code consisting of zip code, telephone number, floor of the ICU and hospital location was used. The data were entered anonymously. No incentives were offered, participation in the survey was voluntary. Randomization or alteration of the items' order of appearance was not carried out. The staffing of the participating ICUs was explicitly asked. A total of 6 questions were used here (see Table 1). Furthermore, the size of the hospital was queried, and the participants had the opportunity to enter further comments in a free text field. Potential participants were informed about the time duration, data privacy, the investigators, and the purpose of the questionnaire according to the CHERRIES criteria. Personal information was not collected or stored. Neither IP-checks, log files nor cookies were used. An ethics committee's approval was not obtained.
The treatment data described above will be published separately.

\section{Results}

During the three-week processing period, 244 ICUs from 1340 (18,2\%) DIVI reporting sites in Germany participated in the survey. Duplicate participation of ICUs and results by those not involved in the treatment of COVID-19 patients were filtered out. This resulted in a dataset size of $n=205$. The completion rate was $73.2 \%$. The distribution of respondents broken down by hospital beds can be found in Figure 1. Detailed results can be found in Table 1, Figure 1, Figure 2 and Figure 3 respectively.

Free text comments pointed out that there were frequent acute bed closures due to nursing shortages. In some cases, the temporary deployment of staff from non-specialist areas and temporary employment agencies was reported.

\section{Discussion}

The results of the survey show that a median intensivistto-patient ratio of 1:8.0 for treatment of non-COVID19 patients was adapted to a goal of 1:5.0 in COVID-19 patients.

Regarding the nurse-to-patient ratio the median target was 1:2.0 in COVID-19 and in non-COVID-19 patients. It must be noted that the results of the study were not normally distributed. Nevertheless, there is evidence that the nurse-to-patient ratio is greater among nurses caring for COVID-19 patients when considering the mean values of our results. This is depicted in Fig. 2. It can be assumed that the adaption of the staffing ratio is due to the significantly increased medical and organizational effort [18]. Due to hygiene procedures and isolation measures, medical care of COVID-19 patients requires significantly more time. Just donning personal protective equipment takes around 3 minutes each time even for experienced and trained staff [19]. Rapid deterioration of the respiratory symptoms is common, so that prompt action is frequently required, for example rapid intubation [20]. The high treatment effort thus justifies the different intensivists-to-patient ratio and reflects the recommendations that have been issued by the DIVI on staffing and equipment of ICUs [21].

Here, too, it can be assumed that this reflects the increased workload when caring for patients with COVID-19 [18]. The legally prescribed minimum nurse-to-patient ratio is $1: 2.5$ patients during dayshifts and 1:3.5 patients during night shifts [1].

Between March 25th and August 01st, these minimum requirements were lifted due to the surge in patients during the COVID-19 pandemic [1]. This suspension 
of the minimum level of nursing care is likely due to the increasing and well-known lack of trained staff. It should also be noted that the qualifications of the nursing staff were not explicitly considered by our questionnaire. Based on the free text comments, the collected data suggest that the targeted nurse-to-patient ratios were only maintained due to the deployment of staff without prior training in intensive care nursing (thus possibly depleting quality of care and endangering patients' outcomes). Studies have indicated that not only the quantity of nursing staff, but especially the level of training has a high impact on the success of the treatment of critically ill patients [22]. It is alarming that the adherence to the minimal nurse-to-patient ratios was met rarely or never in $37.5 \%$ of cases. This also implies that the treatment of COVID-19 patients was carried out below the currently recognized minimum standards [21]. Adherence to intensivist-to-patient ratios reportedly was more common among the respondents of our survey. The limiting factor seems to be the availability of specialist nursing staff. Free text responses have repeatedly indicated that free beds could not be used for the care of COVID-19 patients due to nurse shortage. These findings are reflected by reports in the literatur[3]. There is a distinct relationship between "nurse-to-patient" ratio and patient outcome. A study of 232,342 surgical patients in the USA was able to show that there was a $7 \%$ higher 30-day mortality and an OR of 1.23 for burnout in nurses for each additional patient that needed to be cared for [16]. Further studies confirm these results [15]. Kane and colleagues also confirm these findings for the intensive care unit; in a systematic review it was shown that lower nurse-to-patient ratios were associated with reduced mortality in the critically-ill [10]. Pneumonia, cardiac arrest, respiratory failure, unplanned extubations and the length of stay in intensive care units were reduced by about $24 \%$ [10]. In a German multicenter study Schwab and colleagues were able to show that better care for ventilated patients reduces the risk of nosocomial infections [23]. Additionally, it should be noted that necessary isolation measures increase the cost to the health care system as well as increasing workload for health care professionals thus potentially worsening patient outcomes indirectly [24, 25, 26]. We would like to point out that we did not query whether legal minimum staffing standards were achieved but instead queried whether the pre-determined minimal standard that each individual ICU manager aimed for were met. Neither did we assess the differences between day and night shifts. Regarding physicians, we did not evaluate the exact on-call rotations and schedules of the participating ICUs. The qualifications of the staff weren't considered. As can be seen from the comments, non-intensive-care physicians were recruited to support ICUs and were also counted in.

\section{Conclusions}

In conclusion most of the ICUs increased staffing ratios to meet the challenge of the COVID-19 pandemic and were able to meet target staff-to-patient ratio. However, this seemed to be easier in the case of physicians than in the case of nurses. It is worrisome that in more than a third of the reporting ICUs adequate nurse staffing ratios were not practicable. It seems impossible to resolve this discussion during the ongoing COVID-19 pandemic. Nevertheless, a subsequent discussion on adequate staffing levels in German ICUs is necessary to ensure high-quality, patient-centered care in the future. In addition, illness and burnout among medical staff could thus be reduced. Concepts aiming to increase the appeal of healthcare jobs are desperately needed to be prepared for upcoming challenges in the future and attract highly trained and motivated staff.

\section{Appendix}

\section{Acknowledgements}

The authors thank all participants of the survey for their contribution.

\section{Funding}

The CEOsys project is funded under a scheme issued by the Network of University Medicine (Nationales Forschungsnetzwerk der

Universitätsmedizin (NUM)) by the Federal Ministry of Education and Research of Germany (Bundesministerium für Bildung und Forschung (BMBF)). FKZ: 01KX2021.

\section{Abbreviations}

PpUGV - Pflegepersonaluntergrenzen-Verordnung (German regulation on minimal nurse staffing)

ICU - Intensive Care Unit

DIVI - Deutsche Interdisziplinäre Vereinigung für Intensiv- und

Notfallmedizin (German interdisciplinary society of intensive care medicine)

\section{Availability of data and materials}

The dataset used and analysed during the current study is available from the corresponding author on reasonable request.

Ethics approval and consent to participate

Not applicable.

\section{Competing interests}

The authors declare that they have no competing interests.

Consent for publication

Not applicable.

Authors' contributions

CG SD and OM contributed equally to this work. CG SD drafted the manuscript and analyzed the data with support from AS MP SVR MG. AS MP CS created the survey and contributed to distribution. MG FF PK SL CS SVR created the PICO formated questions. OM conceived the study and revised the manuscript with support from CG SD OM FF PK SL. All authors provided critical feedback and helped shape the research, analysis and manuscript.

\section{Authors' information}

All authors support the current recommendations of the International Committee of Medical Journal Editors (ICMJE). 


\section{Author details}

${ }^{1}$ Department of Anaesthesiology, Emergency and Intensive Care Medicine, University Hospital Goettingen, Georg-August-University, Goettingen, Germany. ${ }^{2}$ Department of Anaesthesia, University Hospital of Wuerzburg, Würzburg, Germany. ${ }^{3}$ Department of Anaesthesiology and Intensive Care Medicine, University of Leipzig Medical Center, Leipzig, Germany. ${ }^{4}$ Institute for Evidence in Medicine (for Cochrane Germany Foundation), Faculty of Medicine and Medical Center-University of Freiburg, Freiburg, Germany.

\section{References}

1. Bundesgesundheitsministerium. Pflegepersonaluntergrenzen; 17.01.2021. Available from: https://www. bundesgesundheitsministerium.de/personaluntergrenzen.html.

2. Stellungnahme zum Referentenentwurf des Bundesministeriums für Gesundheit Verordnung zur Festlegung von Pflegepersonaluntergrenzen in pflegesen-sitiven Krankenhausbereichen für das Jahr 2019 (Pflegepersonaluntergrenzen-Verordnung-PpUGV); 08.02.2021. Available from: https://www.divi.de/joomlatools-files/ docman-files/publikationen/stellungnahmen/ 20181009-DIVI-Stellungnahme-Pflegepersonaluntergrenzen.pdf.

3. Karagiannidis C, Kluge S, Riessen R, Krakau M, Bein T, Janssens U. Auswirkungen des Pflegepersonalmangels auf die intensivmedizinische Versorgungskapazität in Deutschland. Medizinische Klinik Intensivmedizin und Notfallmedizin. 2019;114(4):327-333.

4. Michel J, Hofbeck M, Gerster L, Neunhoeffer F. Personalsituation auf neonatologischen und pädiatrischen Intensivstationen eine europaweite Umfrage. Klin Padiatr. 2019;p. 255-261. Available from: https: //pesquisa.bvsalud.org/portal/resource/\%20es/mdl-31505692.

5. Brücher BLDM, Deufert D. German nursing shortage in hospitals Homemade by Profititis? 4open. 2019;2:3.

6. Marć M, Bartosiewicz A, Burzyńska J, Chmiel Z, Januszewicz P. A nursing shortage - a prospect of global and local policies. International nursing review. 2019;66(1):9-16.

7. Lasater KB, Aiken LH, Sloane DM, French R, Martin B, Reneau K, et al. Chronic hospital nurse understaffing meets COVID-19: an observational study. BMJ Quality \& Safety. 2020;

8. Deutsches Ärzteblatt. 60 Wochenstunden: Niedersachsen hebt Pflegearbeitszeit an; 2020. Available from: https://www. aerzteblatt.de/nachrichten/117956/ 60-Wochenstunden-Niedersachsen-hebt-Pflegearbeitszeit-an

9. Penoyer DA. Nurse staffing and patient outcomes in critical care: a concise review. Critical care medicine. 2010;38(7):1521-8; quiz 1529. Available from: https://pubmed.ncbi.nlm.nih.gov/20473146/.

10. Kane RL, Shamliyan TA, Mueller C, Duval S, Wilt TJ. The association of registered nurse staffing levels and patient outcomes: systematic review and meta-analysis. Medical care. 2007;45(12):1195-1204

11. Stone PW, Mooney-Kane C, Larson EL, Horan T, Glance LG, Zwanziger J, et al. Nurse working conditions and patient safety outcomes. Medical care. 2007;45(6):571-578. Available from: https://pubmed.ncbi.nlm.nih.gov/17515785/.

12. Whitman GR, Kim Y, Davidson LJ, Wolf GA, Wang SL. The impact of staffing on patient outcomes across specialty units. The Journal of nursing administration. 2002;32(12):633-639. Available from: https://pubmed.ncbi.nlm.nih.gov/12483084/.

13. Aiken LH, Sloane DM, Bruyneel L, van den Heede K, Griffiths P, Busse $R$, et al. Nurse staffing and education and hospital mortality in nine European countries: a retrospective observational study. The Lancet. 2014;383(9931):1824-1830.

14. Rothschild JM, Bates DW, Franz C, Soukup JR, Kaushal R. The costs and savings associated with prevention of adverse events by critical care nurses. Journal of Critical Care. 2009;24(3):471.e1-7.

15. Shin S, Park JH, Bae SH. Nurse staffing and nurse outcomes: A systematic review and meta-analysis. Nursing outlook. 2018;66(3):273-282.

16. Aiken LH, Clarke SP, Sloane DM, Sochalski J, Silber JH. Hospital nurse staffing and patient mortality, nurse burnout, and job dissatisfaction. JAMA. 2002;288(16):1987-1993. Available from: https://pubmed.ncbi.nlm.nih.gov/12387650/.

17. Lasater KB, McHugh M, Rosenbaum PR, Aiken LH, Smith H, Reiter JG, et al. Valuing hospital investments in nursing: multistate matched-cohort study of surgical patients. BMJ Quality \& Safety.
2021;30(1):46-55. Available from:

https://qualitysafety.bmj.com/content/early/2020/03/26/ bmjqs-2019-010534. info?versioned=true.

18. Vergano M, Bertolini G, Giannini A, Gristina GR, Livigni S, Mistraletti $G$, et al. Clinical ethics recommendations for the allocation of intensive care treatments in exceptional, resource-limited circumstances: the Italian perspective during the COVID-19 epidemic. Critical Care. 2020;24(1):165

19. Goldman R, Virani AK. The 3-Minute Ethical Dilemma: Using Personal Protective Equipment Puts Healthcare Providers in the Crossfire of Duty to Care and Staying Healthy. Pediatric emergency care. 2020;36(10):505-507.

20. Pfeifer M, Ewig S, Voshaar T, Randerath WJ, Bauer T, Geiseler J, et al. Position Paper for the State-of-the-Art Application of Respiratory Support in Patients with COVID-19. Respiration; international review of thoracic diseases. 2020;99(6):521-542.

21. Jorch G, Kluge S, König F, Markewitz A, Notz K, Parvu V, et al. Empfehlungen zur Struktur und Ausstattung von Intensivstationen. Deutsche Interdisziplinäre Vereinigung für Intensiv-und Notfallmedizin. 2010;.

22. Harrison JM, Aiken LH, Sloane DM, Brooks Carthon JM, Merchant RM, Berg RA, et al. In Hospitals With More Nurses Who Have Baccalaureate Degrees, Better Outcomes For Patients After Cardiac Arrest. Health affairs (Project Hope). 2019;38(7):1087-1094.

23. Schwab F, Meyer E, Geffers C, Gastmeier P. Understaffing, overcrowding, inappropriate nurse:ventilated patient ratio and nosocomial infections: which parameter is the best reflection of deficits? The Journal of hospital infection. 2012;80(2):133-139. Available from: http://www.sciencedirect.com/science/article/ pii/S019567011100449X

24. Poulakou G, Nseir S, Daikos GL. Less contact isolation is more in the ICU: pro. Intensive Care Medicine. 2020;46(9):1727-1731.

25. Sprague E, Reynolds S, Brindley P. Patient Isolation Precautions: Are They Worth It? Canadian respiratory journal. 2016;2016:5352625.

26. Abad C, Fearday A, Safdar N. Adverse effects of isolation in hospitalised patients: a systematic review. The Journal of hospital infection. 2010;76(2):97-102. Available from: http://www. sciencedirect.com/science/article/pii/S0195670110002446.

Figures

Figure 1 respondents by numbers of hospital beds

Figure 2 Targeted staffing ratios (mean value) between physicians and patients or nurses and patients divided by COVID-19 and non-COVID-19 treatment

Figure 3 Proportions of adherence to targeted staffing ratios in the ICU divided by medical and nursing staff 
Tables

\begin{tabular}{|c|c|c|c|}
\hline Questions posed to ICU managers in the online survey & Mode & n (\%) & Median (IQR) \\
\hline $\begin{array}{l}\text { What is the maximum number of ICU patients you are aiming for that will be cared for by } \\
\text { one physician? }\end{array}$ & numerical & 168 & $8.0(4.0)$ \\
\hline $\begin{array}{l}\text { What is the maximum number of ICU COVID-19 patients you are aiming for that will be } \\
\text { cared for by one physician? }\end{array}$ & numerical & 169 & $6.0(2.0)$ \\
\hline $\begin{array}{l}\text { What is the maximum number of ICU patients you are aiming for that will be cared for by } \\
\text { one nurse? }\end{array}$ & numerical & 150 & $2.0(1.0)$ \\
\hline $\begin{array}{l}\text { What is the maximum number of ICU COVID-19 patients you are aiming for that will be } \\
\text { cared for by one nurse? }\end{array}$ & numerical & 157 & $2.0(0)$ \\
\hline $\begin{array}{l}\text { To what extent do you succeed in implementing the above staffing ratio among medical } \\
\text { staff? }\end{array}$ & $\begin{array}{l}\text { Multiple Choice } \\
\text { - Always } \\
\text { - Often } \\
\text { - Rarely } \\
\text { - Never }\end{array}$ & $\begin{array}{l}171 \\
28(16.4) \\
110(64.3) \\
26(15.2) \\
6(3.5)\end{array}$ & \\
\hline $\begin{array}{l}\text { To what extent do you succeed in implementing the above-mentioned staffing ratio among } \\
\text { nursing staff? }\end{array}$ & $\begin{array}{l}\text { Multiple Choice } \\
\text { - Always } \\
\text { - Often } \\
\text { - Rarely } \\
\text { - Never }\end{array}$ & $\begin{array}{l}171 \\
13(7.6) \\
93(54.4) \\
55(32.2) \\
9(5.3)\end{array}$ & \\
\hline
\end{tabular}


Figures

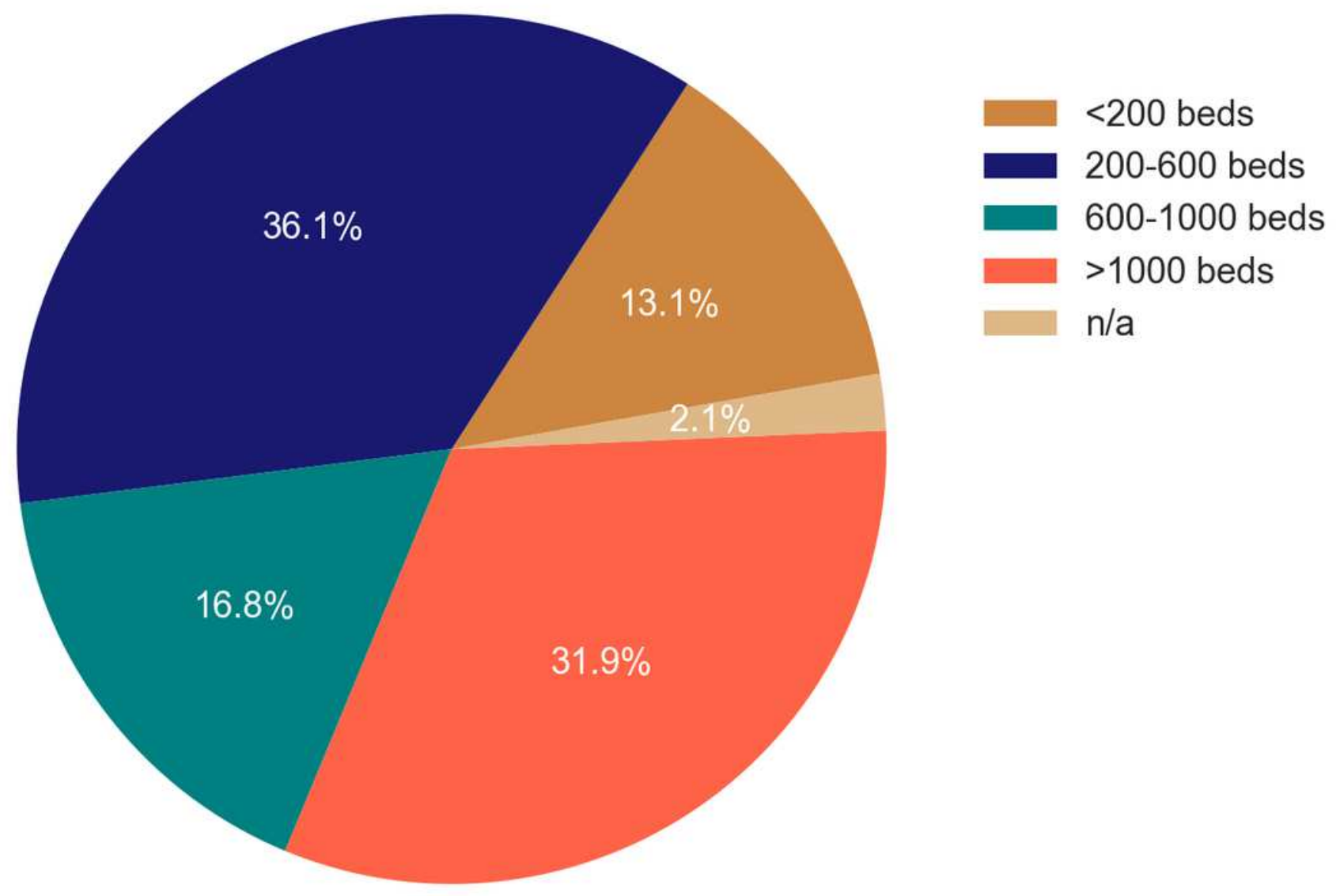

Figure 1

respondents by numbers of hospital beds 


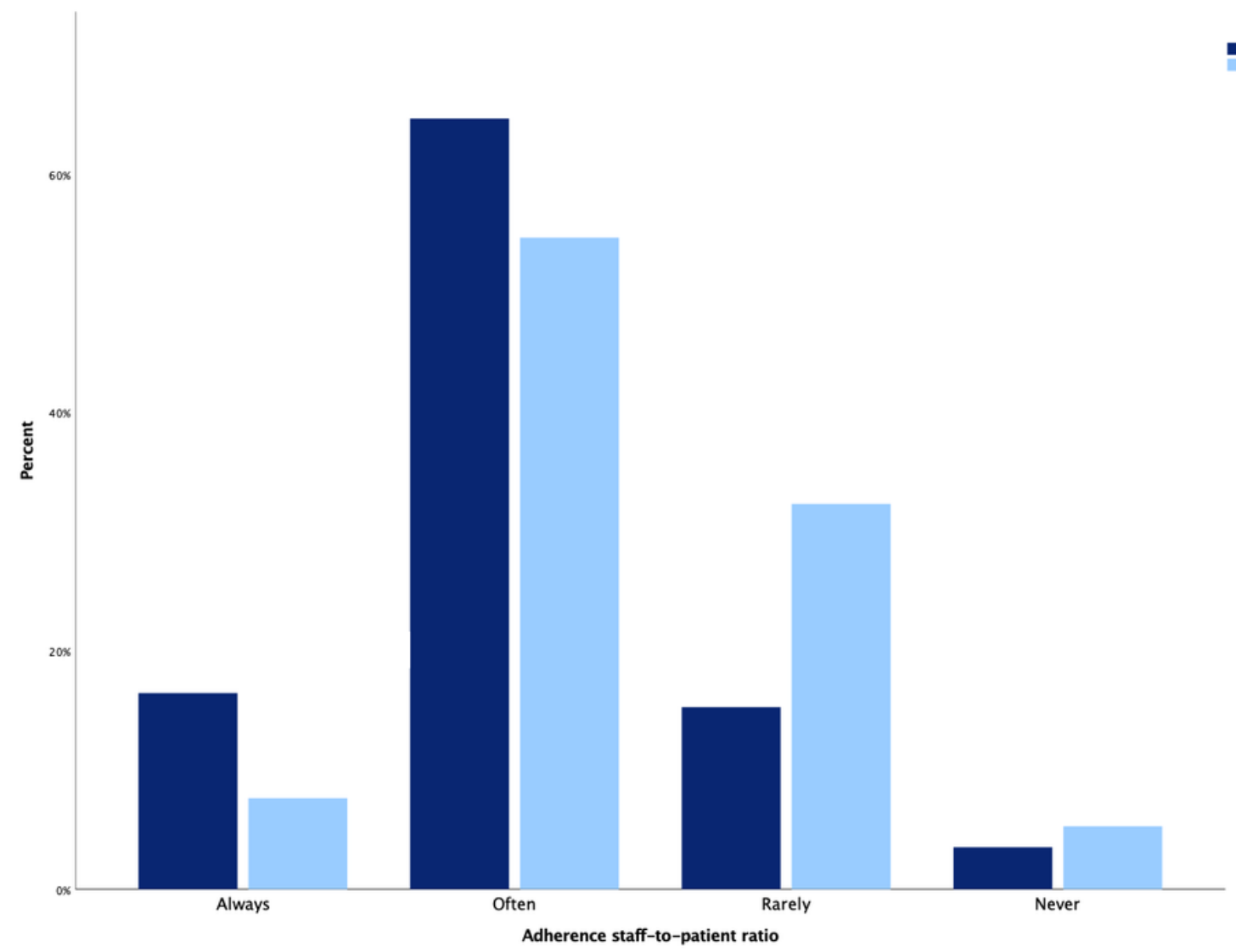

Figure 2

Targeted staffing ratios (mean value) between physicians and patients or nurses and patients divided by COVID-19 and non-COVID-19 treatment 


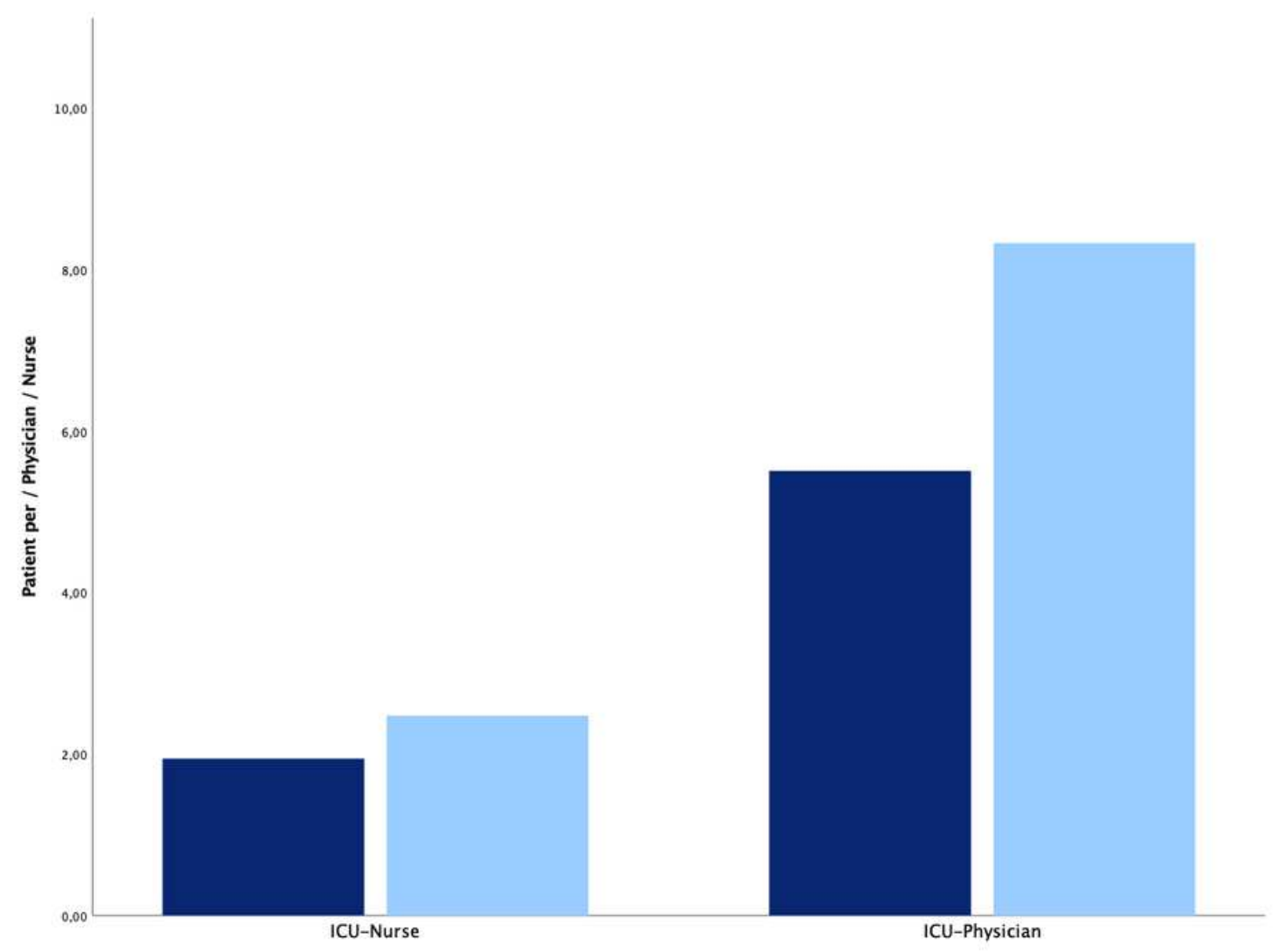

Figure 3

Proportions of adherence to targeted staffing ratios in the ICU divided by medical and nursing staff 